\title{
Simulation and experimental research on droplet flow characteristics and deposition in airflow field
}

\author{
Bing Xiahou ${ }^{1}$, Daozong Sun ${ }^{2,3,4,5}$, Shuran Song ${ }^{2,3,4,5^{*}}$, Xiuyun Xue ${ }^{2,3,4,5}$, Qiufang Dai ${ }^{2,3,4,5}$ \\ (1. Logistics Department, South China Agricultural University, Guangzhou 510642, China; \\ 2. College of Electronic Engineering, College of Artificial Intelligence, South China Agricultural University, Guangzhou 510642, China; \\ 3. Division of Citrus Machinery, China Agriculture Research System, Guangzhou 510642, China; \\ 4. Guangdong Engineering Research Center for Monitoring Agricultural Information, Guangzhou 510642, China; \\ 5. Guangdong Engineering Technology Research Center for Mountainous Orchard Machinery, Guangzhou 510642, China)
}

\begin{abstract}
In order to study the motion law of droplet flow under the airflow action of long-range air-blast sprayers, a CFD-based 3D model was established for the air-blast sprayer duct and its external airflow field, and the discrete phase model was introduced to simulate the motion of droplet flow in the airflow. The simulation data of the droplet flow trajectory, droplet flow parameters and droplet deposition were obtained by establishing the monitoring sections and bilateral coupling calculation in the airflow field. Results showed that gravity had an obvious effect on droplets and large droplets settled faster. Some of the larger droplets were formed by polymerization in droplets motion. The smaller droplets were transported further along with the airflow, and the long-range sprayer has a significant effect on the directional transport of small droplets. Besides, the spraying swath in the direction perpendicular to the range enlarged gradually with the increase of the spraying range. At the end of the range, the diffuse and drifting of the droplets were dominant. Given that the outlet airflow velocity of the sprayer duct was $25.01 \mathrm{~m} / \mathrm{s}$ and the spray pressure $1.8 \mathrm{MPa}$, the maximum motion distances of aerosol, mist, fine mist and coarse mist in the airflow field were $18.5 \mathrm{~m}, 19.5 \mathrm{~m}, 17.5 \mathrm{~m}$ and $10.5 \mathrm{~m}$, respectively. Droplet size and number as well as number density and volume density of droplet flow on all monitoring sections showed a regression function with changes in the distance of the spraying range. The simulation results of the model adopted in this paper were verified by Chi-square test between the simulation results of the droplet deposition and the spray measurement results. Research results provide a new method for the study of orchard air-blast spraying technology and references for the optimization of spraying technology.
\end{abstract}

Keywords: droplet flow, droplet density, air-blast sprayer, computational fluid dynamics, droplet deposition DOI: $10.25165 /$ j.ijabe.20201306.5455

Citation: Xiahou B, Sun D Z, Song S R, Xue X Y, Dai Q F. Simulation and experimental research on droplet flow characteristics and deposition in airflow field. Int J Agric \& Biol Eng, 2020; 13(6): 16-24.

\section{Introduction}

Air-blast spraying technology crushes pesticide droplets using high speed airflow produced by fans and transports them to the target. It can enhance droplets penetrability, improve uniformity and coverage of droplets on the target, and also effectively reduce droplets drift and pesticide drift and realize low volume spraying $^{[1-3]}$. Spraying quality and effect is closely related to size, drift and settling velocity of droplets, while droplet size plays a decisive role. The increase in droplet size has a positive effect on the settling property. But large droplets are distributed unevenly and can fall into soil easily. The smaller droplet is the better

Received date: 2019-10-11 Accepted date: 2020-06-22

Biographies: Bing Xiahou, MS, Engineer, research interests: agricultural engineering technology and precision spraying technology. Email: 346593633@qq.com; Daozong Sun, PhD, Associate Professor, research interests: agricultural engineering application of embedded system and water-saving irrigation technology. Email: sundaozong@scau.edu.cn; Xiuyun Xue, $\mathrm{PhD}$ candidate, Senior Laboratory Technician, research interests: agricultural engineering technology and precision spraying technology. Email: 59113829@qq.com; Qiufang Dai, PhD, Lecturer, research interests: spraying equipment and its key technology. Email: 149960069@qq.com.

*Corresponding author: Shuran Song, $\mathrm{PhD}$, Professor, research interests: spraying technology and measurement and control technology. College of Electronic Engineering/ College of Artificial Intelligence, South China Agricultural University, Guangzhou 510642, China. Tel: +86-13668966908, Email: songshuran@scau.edu.cn. penetrability is and can settle and cover crops evenly. However, small droplets can hardly settle but drift under the effect of airflow. As a result, the environment will be easily polluted and the health of humans and livestock will be endangered ${ }^{[4]}$.

At present, the researches on air-blast spraying technology mainly focused on front end and rear end of sprayer. Front end refers to structure parameters and flow field law of fan and rear end refers to drift and deposition law of droplets.

As for front end research, Guo et al. ${ }^{[5]}$ studied 3D modeling and simulation of orchard air-blast sprayer with CFD (Computational Fluid Dynamics) to optimize the airflow inside the sprayer. Liu et al. ${ }^{[6]}$ installed a fluid director at the outlet of 9WZCD-25 type air-blast sprayer, which improved uniformity and density distribution of droplets and partly raised the spraying swath Ding et al. ${ }^{[7]}$ analyzed the distribution of airflow inside single and double air ducts through CFD numerical simulation and experiment by using a viscous-standard model. Fu et al ${ }^{[8]}$ established the velocity distribution model of airflow field of Hardi LB-255 type orchard air-blast sprayer through CFD simulation. Song et al..$^{[9-12]}$ studied the airflow field inside air-blast sprayer to optimize the structure of long-range duct and wide-swath duct through CFD numerical simulation. Chen et al. ${ }^{[13]}$ studied distribution character of airflow velocity field of disk fan of orchard air-blast sprayer using $k-\varepsilon$ turbulent model and steady-state solution method and carried out $3 \mathrm{D}$ steady numerical simulation and experimental verification of airflow velocity field of single and double fans. 
Endalew et al. ${ }^{[14]}$ established a 3D model of orchard two-fan mixed flow air-blast sprayer with CFD technology and based on this predicted the distribution of airflow velocity in areas with different crown densities. Delele et al. ${ }^{[15]}$ studied the effect of moving speed of the sprayer on 3D airflow pattern of crossflow type air-blast sprayer by using CFD model. Dekeyser et al. ${ }^{[16]}$ had studied seven kinds of spray technology parameters such as different types of sprayers, fan speed and deflectors, etc., compared the droplet deposition amount in the target fruit tree and the droplet loss from the target fruit tree, and verified the CFD orchard spray model.

As for rear end research, Qi et al. ${ }^{[17]}$ based on the boundary conditions and parameters of 2D flow field and established the droplet deposition and distribution model of Hardi LB-255 type orchard air-blast sprayer using CFD technology. Cui et al. ${ }^{[18]}$ designed and installed conical duct and coaxial column duct for sprayer outlet and studied the effect of the structure of air-blast sprayer duct on the drifting property through CFD 2D modeling. Wang et al. ${ }^{[19]}$ studied the effect of airflow around the application object (target) on trajectory and adhesive behavior (deposition rate) of droplets through CFD simulation. $\mathrm{Lv}$ et al. ${ }^{[20,21]}$ studied drifting property and deposition distribution of droplets in a controllable airflow tunnel according to different parameters of spraying technology. He et al. ${ }^{[22]}$ studied the effect of change law of airflow velocity on pesticide deposition on the target and concluded that penetrability and deposition of droplets in the tree canopy were positively related to airflow velocity. Delele et al. ${ }^{[23]}$ compared the distribution of droplets produced by different nozzles of air-blast cross-flow sprayer with CFD model to maximize the deposition effect of the target and reduce the risk of environmental pollution. Salyani et al. ${ }^{[2]}$ conducted spray experiment with different numbers and sizes of nozzles and studied how to increase the deposition rate of spray. Larbi et al. ${ }^{[25]}$ developed a simulation model to predict the target droplet deposition of mandarin, and field experiments were carried out to verify the model. Ramon et al. $^{[26]}$ used 2D computational fluid dynamics (CFD) model to determine the droplet model of citrus trees during pesticide spraying. The simulation results showed that $44 \%$ of the droplets reached the target tree, $28 \%$ reached the adjacent trees, $20 \%$ were deposited on the ground, and $8 \%$ were lost as atmospheric drift. The simulation results were basically matched with the experimental results.

Previous researches mainly focused on the structure of air-blast sprayer or optimization of spraying effect but less on the motion law of droplet flow in the airflow field. General change laws of density and other parameters of droplet flow of long-range air-blast sprayer in the airflow field were figured out using Fluent (Computational Fluid Dynamics Software) and through regression analysis in this paper, which provided references for improvement of air-blast spraying technology.

\section{Simulation hypothesis and model selection}

In general, two-phase flow and multiphase flow models simulate the motion of principal phase and dispersed phase by using Euler-Euler Method. It's better to describe dispersed phase particles through Lagrangian Method when more attention should be paid to the trajectory of dispersed phase particles ${ }^{[27]}$. Fluent Discrete Phase Model (DPM) adopts Euler-Lagrangian Method and simulates the second phase of dispersed phase in the flow field through Lagrangian Method while the transport equation of continuous phase is figured out through Euler Method. It can also be used to analyze mist spray, particle flow, pulverized coal firing, particle separation and liquid fuel combustion, etc. ${ }^{[28]}$

Previous experiment ${ }^{[29]}$ showed that the research object of this paper featured that: it was two-phase flow, namely air and liquid. The liquid was droplets (dispersed), and droplets began to atomize and disperse at the initial position of the airflow field and droplet flow was formed in the airflow. Thus, the motion of droplet flow in the airflow field was simulated and studied using DPM, which was closer to the actual motion state of droplet flow in the airflow field than that with the two-phase flow or multiphase flow models.

Fluent DPM figured out the trajectory of dispersed phase droplet through Lagrangian Method and the action force balance equation of droplet (Inertial force of droplet is equal to all forces acted on droplet) in Cartesian coordinate system (direction $y$ is the direction of gravity) is shown below:

$$
\begin{gathered}
\frac{d u_{p}}{d t}=F_{D}\left(u-u_{p}\right)+\frac{g_{y}\left(\rho_{p}-\rho\right)}{\rho_{p}}+F_{y} \\
F_{D}=\frac{18 \mu}{\rho_{p} d_{p}^{2}} \frac{C_{D} \operatorname{Re}}{24} \\
\operatorname{Re}=\frac{\rho d_{p}\left|u_{p}-u\right|}{\mu} \\
C_{D}=\alpha_{1}+\frac{\alpha_{2}}{\operatorname{Re}_{\mathrm{e}}}+\frac{\alpha_{3}}{\operatorname{Re}^{2}}
\end{gathered}
$$

where, $u$ is the airflow velocity, $\mathrm{m} / \mathrm{s} ; u_{p}$ is the droplet velocity, $\mathrm{m} / \mathrm{s}$; $\mu$ is the airflow viscosity, $\mathrm{Pa} \cdot \mathrm{s} ; \rho$ is the airflow density, $\mathrm{kg} / \mathrm{m}^{3} ; \rho_{p}$ is the skeletal density of droplet, $\mathrm{kg} / \mathrm{m}^{3} ; d_{p}$ is the droplet diameter, $\mathrm{m}$; $\mathrm{Re}$ is the dimensionless relative Reynolds number (droplet Reynolds number); $C_{D}$ is the dimensionless drag coefficient; $g_{y}$ is the gravitational acceleration in direction $y, \mathrm{~m} / \mathrm{s}^{2} ; F_{D}(u-u p)$ is the drag force per mass of droplet, $\mathrm{N} ; F_{y}$ is other action forces in direction $y, \mathrm{~N} ; \alpha_{1}, \alpha_{2}$ and $\alpha_{3}$ are dimensionless constants ${ }^{[27]}$.

\section{Setting of initial conditions for simulation calculation}

\subsection{Setting of 3D modeling for sprayer-duct and its external airflow field}

Upon actual measurement, the sprayer-duct outlet diameter of the D400 air-blast sprayer model machine studied in this paper was $0.345 \mathrm{~m}$, the average airflow velocity at the sprayer-duct outlet was $25.01 \mathrm{~m} / \mathrm{s}$ and the maximum spraying swath vertical to the spraying range direction was $2.29 \mathrm{~m}^{[29]}$.

Set a cylinder with $0.345 \mathrm{~m}$ in diameter and $0.525 \mathrm{~m}$ in length to represent the sprayer- duct model machine (suppose inner wall of the sprayer-duct is smooth, friction coefficient is 0). According to previous experiment ${ }^{[29]}$, suppose the largest motion area of droplet flow is a cuboid whose length is $20 \mathrm{~m}$, width is $2.29 \mathrm{~m}$ (the maximum spraying swath vertical to the spraying range direction is $2.29 \mathrm{~m}$ ) and height is $2.68 \mathrm{~m}$ (the sum of the sprayer-duct axis is $1.53 \mathrm{~m}$ above the ground and half of the maximum spraying swath vertical to the spraying range direction is $1.15 \mathrm{~m}$ ). Through repeated calculation and comparison, the width and height of $3 \mathrm{D}$ model of the computational domain were set to triple and double ranges of the maximum motion area of droplet flow in order to reduce the influence of boundary wall on the airflow field and droplet flow. In addition, the Boundary Wall property was set to open boundary condition, when the droplets reach the boundary wall, they will escape and will not react to the original droplet flow, so as to be closer to the actual working conditions. 
This study was intended to simulate the motion trajectory and relevant parameters of droplet flow in the airflow field. In order to reduce the load of computer hardware, improve the quality of grids, cut down the number of grids and consequently effectively elevate computational efficiency and accuracy. Suppose $x$ was the axial direction when the sprayer-duct was placed horizontally, $y$ was the direction opposite to the gravity and $x, y$ and $z$ made up a Cartesian coordinate system, with xoy plane as the symmetry plane, 3D model of the sprayer-duct and its external airflow field was divided into two parts and the semi-symmetry model in the positive direction of $z$-axis was studied and analyzed in this study. Then the semi-symmetry model was divided into four parts for mesh generation: zone I was the area where the sprayer-duct was located, zone II was the $0 \mathrm{~m}<x \leq 1 \mathrm{~m}$ area, zone III was the $1 \mathrm{~m}<x \leq 20 \mathrm{~m}$ area and zone IV was the rest area of all computational domains subtracting by zones I, II and III. The half of the sprayer-duct in zone I was out-of-shape and was divided by unstructured grids, the space between grids was $0.06 \mathrm{~m}$. Since unstructured grids have better self-adaptation ${ }^{[30]}$ and zone II were connected with zone I, so zone II was also divided by unstructured grid to better connect grids with zones I and the space between grids was $0.18 \mathrm{~m}$. In order to effectively cut down the number of grids and improve the computational efficiency, zones III and IV were divided by structured grid and the space between grids in zone III was also $0.18 \mathrm{~m}$ and that in zone IV was $0.8 \mathrm{~m}$. It should be noted that the joint face of zone I and zone II, both of which were unstructured grids, should be set as interior; while zone II was an unstructured grid and zone III was a structured grid, and data of fluid regions cannot be exchanged, so it's necessary to set the joint face of zone II and zone III as interface before fluent numerical calculation was conducted to realize data exchange between unstructured grid and structured grid $^{[31]}$. Similarly, the joint face between zones II, III and IV should be set.

The 3D grid semi-symmetric model of the sprayer-duct and its external airflow field were modeled and meshed by Gambit2.4.6, as shown in Figure 1. The number of cells, faces and nodes in the model are 14 508, 46425 and 14 183, respectively.

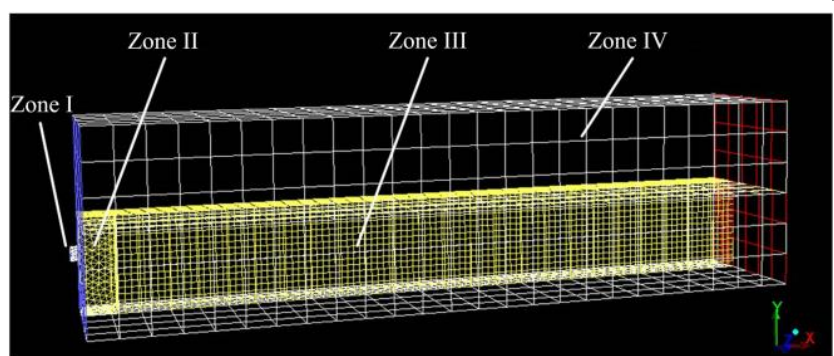

Figure $13 \mathrm{D}$ grid semi-symmetry model of the sprayer-duct and its external airflow field

\subsection{Assumption and setting of airflow velocity field}

To simplify the model and improve the computational efficiency, set the following assumptions: (1) Airflow was vertical to the sprayer-duct outlet, namely airflow had a component only in the positive direction of $x$-axis; (2) Airflow velocity at the sprayer-duct outlet remained constant at $25.01 \mathrm{~m} / \mathrm{s}$; (3) Airflow in the droplet flow motion area was incompressible.

Fluent version 14.5 and standard turbulence model k- $\varepsilon$ equation were used in numerical calculations. The Standard Wall Functions were selected for turbulence model and the effect of gravity on droplets was considered. Pressure-velocity coupling was calculated by using Pressure-Based Solver of Fluent 3D module and Simple algorithm and the magnitude order of residuals was set as $10^{-6}$ to ensure the computational accuracy.

The setting of boundary conditions: The sprayer-duct inlet was set as velocity-inlet and other inlets were set as pressure-inlet (blue grids in Figure 1). Boundary conditions of the outlet were set as pressure-outlet (red grids in Figure 1) and other boundary conditions were set as wall.

\subsection{Setting of spray model}

Droplets were produced by 10 hollow conical nozzles with outlet diameter of $0.85 \mathrm{~mm}$ evenly distributed around the circular sprayer-duct outlet at a $36^{\circ}$ central angle, the axis of each nozzle was vertical to the sprayer-duct circumference and declined for $15^{\circ}$ to the sprayer-duct axis, the linear distance between nozzles was $11.2 \mathrm{~cm}$, every 2 of 10 nozzles were grouped and 5 groups were evenly distributed around the sprayer-duct outlet at different heights. The nozzles were distributed as shown in Figure 2. The experiment result showed that the flow rate of single nozzle was $0.0286 \mathrm{~kg} / \mathrm{s}$, the spray cone angle of nozzle was $\alpha=70^{\circ}$ and the spray pressure was $1.8 \mathrm{MPa}^{[29]}$. According to distribution and parameters of the aforesaid nozzles, the corresponding initial settings of the simulated injection sources can be made.
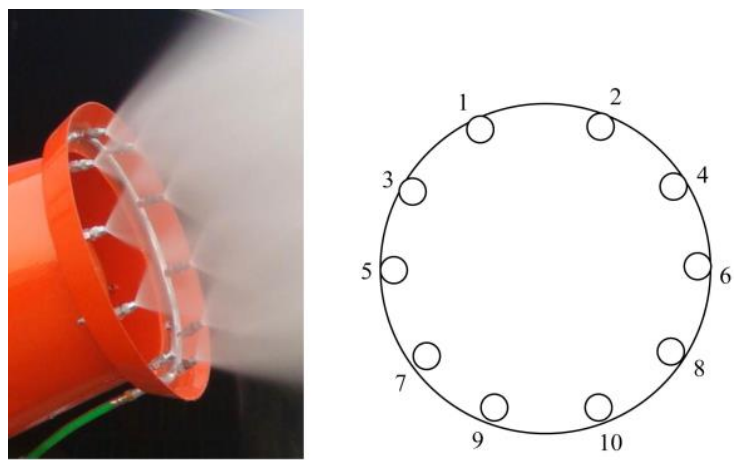

Figure 2 Distribution of nozzle at the sprayer-duct outlet

According to preliminary results of experiments, actual spraying effect and characteristics of nozzle, the working mechanism of pressure-swirl atomizer in DPM model ${ }^{[32]}$ best coincided with characteristics of hollow conical nozzle, so it was adopted for simulated experiment to simulate burst and merge of droplets and trajectory of droplets.

When the trajectory of droplet flow was calculated, gain and loss on heat, mass and momentum of dispersed phase droplets along the trajectory acted on the continuous phase simultaneously. Therefore, the coupling between dispersed phase and continuous phase cannot be ignored. Calculations with continuous phase and dispersed phase successively and in consideration of the mutual effect between dispersed phase and continuous phase, figured out the governing equation alternately until the computational solutions converged, so as to realize bidirectional coupling calculation.

Variation of droplet momentum is:

$$
F=\sum\left(\frac{18 \beta \mu C_{D} \operatorname{Re}}{\rho_{p} d_{p}^{2} 24}\left(u_{p}-u\right)+F_{\text {other }}\right) \dot{m}_{p} \Delta t
$$

Variation of droplet heat:

$$
Q=\left[\frac{\overline{m_{p}}}{m_{p, 0}} c_{p} \Delta T_{p}+\frac{\Delta m_{p}}{m_{p, 0}}\left(-h_{f g}+h_{p y r o l}+\int_{T_{r f}}^{T_{p}} c_{p, i} d T\right)\right] \dot{m}_{p, 0}
$$

Variation of droplet mass:

$$
M=\frac{\Delta m_{p}}{m_{p, 0}} \dot{m}_{p, 0}
$$

where, $\beta$ is fluid volume fraction, dimensionless parameter; $u_{p}$ is the velocity of droplet, $\mathrm{m} / \mathrm{s} ; \dot{m}_{p}$ is the mass flow rate, $\mathrm{kg} / \mathrm{s} ; \Delta t$ is 
the time step, s; $F_{\text {other }}$ is the force among other phases, $\mathrm{N} ; \overline{m_{p}}$ is the average mass of droplet, $\mathrm{kg} ; m_{p, 0}$ is the initial mass of droplet, $\mathrm{kg} ; c_{p}$ is the specific heat capacity of droplet, $\mathrm{J} /(\mathrm{kg} \cdot \mathrm{K}) ; \Delta T_{p}$ is the temperature variation of droplet, $\mathrm{K} ; \Delta m_{p}$ is mass variation of droplet, $\mathrm{kg} ; h_{f g}$ is the latent heat from volatilization and separation, $\mathrm{J} / \mathrm{kg} ; h_{\text {pyrol }}$ is the heat needed for pyrolysis during volatilization and separation, $\mathrm{J} / \mathrm{kg} ; c_{p, i}$ is the specific heat of volatilization and separation, $\mathrm{J} /(\mathrm{kg} \cdot \mathrm{K}) ; T_{p}$ is the temperature of droplet, $\mathrm{K} ; T_{r e f}$ is the reference temperature corresponding to enthalpy, $\mathrm{K} ; \dot{m}_{p, 0}$ is the initial mass flow rate of droplet, $\mathrm{kg} / \mathrm{s}^{[32]}$.

The setting of dispersed phase: the interaction mode of DPM was set as interaction with continuous phase. The accuracy of the droplet drag coefficient was the key to simulate the atomization process more accurately. Dynamic-Drag model is based on change of droplet shape to determine the drag coefficient dynamically $^{[32]}$, so Dynamic-Drag model was used in this paper. Considering the effect of droplet burst and merge, droplets were disposed of using Unsteady Particle Tracking and physical model of Droplet Collision and Droplet Breakup were adopted. Tab model is a typical method which is used to calculate droplet burst and merge and has been used to calculate many engineering jet flows $^{[28]}$. Thus, Tab Model was used in this study.

\section{Simulation results and discussion}

\subsection{Calculation result and analysis of droplet flow trajectory}

In order to intuitively analyze change law of droplet flow trajectory under the airflow action of long-range air-blast sprayer, side view and top view of droplet flow trajectory were drawn, as shown in Figure 3.
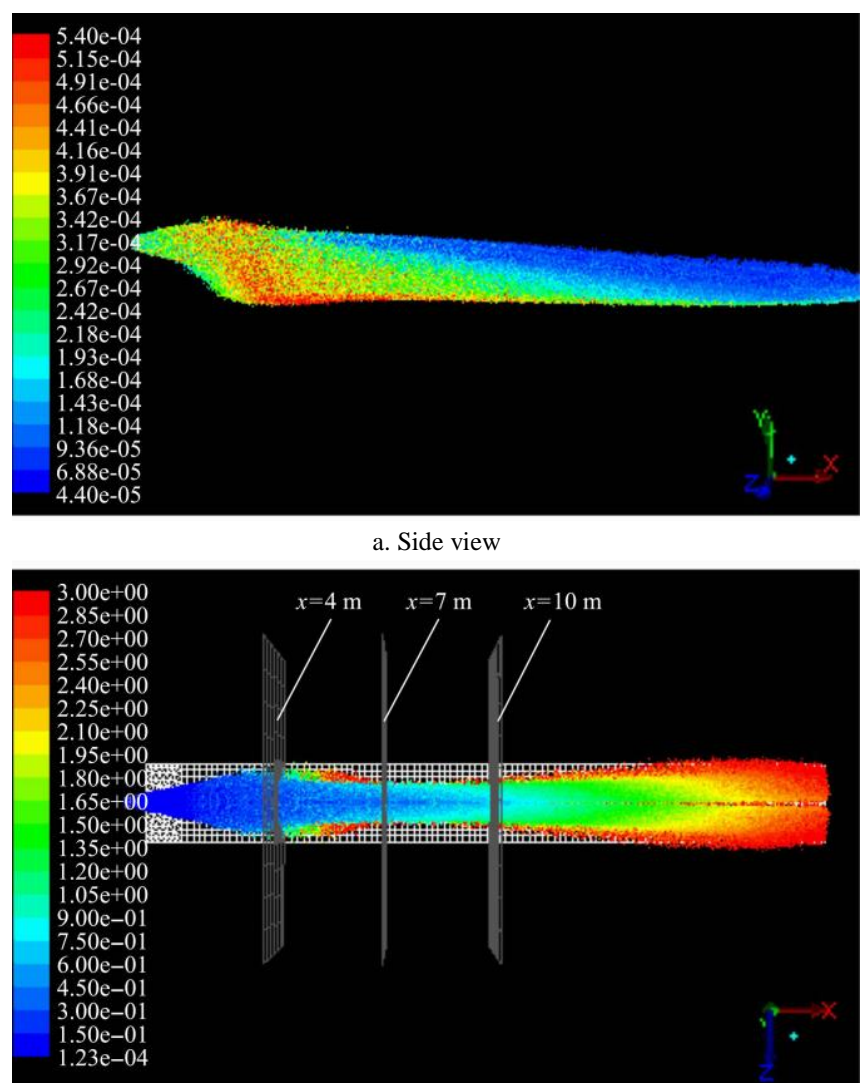

b. Top view

Figure 3 Trajectory distribution of droplet flow

As shown in Figure 3a, on the monitoring section of the same distance of spraying range, the droplet size in $y$-axis changed. That is, the droplet size lower was larger than that of upper, the droplet size was distributed hierarchically, large droplets settled in the bottom layer and small droplets suspended in the top layer and were transported by airflow farther. It's mainly because droplets in the airflow field not only were pushed by airflow in $x$-axis but also were affected by gravity, air buoyancy and inertial resistance in $y$-axis according to Stokes Law $^{[33]}$ :

$$
w=\frac{2 g_{y}\left(\rho_{p}-\rho\right) r^{2}}{9 \mu}
$$

where, $w$ is the settling speed of droplet, $\mathrm{m} / \mathrm{s} ; r$ is the radius of droplet, $\mathrm{m}$.

It is visible from Equation (8) that settling speed of droplet was directly proportional to the square of its droplet size. The larger droplet size was the greater settling speed was. In addition, it can be seen from Figure $3 \mathrm{a}$ that large droplets settled faster. Thus, large droplets can settle easily under the action of gravity. Besides, when accelerating settling under the action of gravity upper droplets collided with lower droplets and both aggregated into larger droplets. Nevertheless, it's easier for small droplets to achieve a balance between gravity and air buoyancy so that they can be transported farther under the airflow action. Therefore, small droplets can be transported by airflow farther, namely long-range air-blast sprayer had a significant effect on directional transport of small droplets.

As shown in Figure 3, the change of droplet size can be observed intuitively through the droplet flow trajectory distribution diagram. Liquid ejected from the nozzles formed dispersed (there were initial velocity components in $x-, y$ - and $z$ - axes) and unequigranular droplets and droplets were driven by airflow at the sprayer-duct outlet to move. With xoy plane as the symmetry plane, the droplet flow trajectory in the positive direction of $z$-axis was mapped to the negative direction of $z$-axis, so the droplet flow trajectory in Figure $3 \mathrm{~b}$ was a complete symmetric figure. As shown in Figure 3b, the diffusion of droplet flow in the spraying range direction can be divided into four zones: 1) The spraying swath of droplets vertical to the spraying range direction gradually enlarged with the increase of $x$-axis, when the range was $x \leq 4 \mathrm{~m}$, it's mainly because the initial velocity component along $z$-axis was relatively large when droplets were sprayed from the nozzle. Thus, droplets showed obvious motion features in z-axis; 2) When the range was $4 \mathrm{~m}<x \leq 7 \mathrm{~m}$, the larger spraying swath decreased because the velocity component along $z$ axis had decreased to a lower value and that along $x$-axis was still high; 3 ) When the range was $7 \mathrm{~m}<x \leq 10 \mathrm{~m}$, the velocity component along $z$-axis remained low and that along $x$-axis was still high even though it gradually decreased with increase in the distance from the sprayer-duct outlet. Droplets were driven by airflow to move fast in the positive direction of $x$-axis and droplets showed unobvious motion features in $z$-axis, so the spraying swath basically remained unchanged; 4) When the range was $x>10 \mathrm{~m}$, the spraying swath of droplets vertical to the spraying range direction gradually increased at the end of the range. It's mainly because that as droplets were farther from the sprayer-duct outlet, the velocity of airflow produced by the sprayer-duct heavily weakened and droplets showed increasingly obvious motion features in $z$-axis. Thus, droplet flow mainly pervaded and drifted at the end of the range.

In order to intuitively analyze change law of the motion time of droplet flow under the airflow action of long-range air-blast sprayer, a motion time diagram was drawn, as shown in Figure 4.

As shown in Figure 4, in the motion direction of $x$-axis droplet flow passed through dark blue zone, light blue zone, green zone, yellow zone and red zone respectively, which represented the time 
taken to pass through each zone, unit as seconds. 1) When the range was $0 \mathrm{~m}<x \leq 4 \mathrm{~m}$, the airflow velocity was relatively large and droplets were driven by airflow to move forward quickly since droplets were close to the sprayer-duct outlet. So it took a short time to reach the zone and the time taken to pass through the dark blue zone was $1.23 \times 10^{-4}-3.0 \times 10^{-1} \mathrm{~s}$; 2) When the range was $4 \mathrm{~m}<$ $x \leq 10 \mathrm{~m}$, as droplets got farther from the sprayer-duct outlet, the airflow velocity gradually decreased and droplets were driven by airflow to move forward less quickly. The time taken by droplets to reach the zone was the time taken to pass through the light blue zone, namely $0.45-0.9 \mathrm{~s}$; 3 ) When the range was $10 \mathrm{~m}<x \leq 14 \mathrm{~m}$, the airflow velocity further decreased and the time taken by droplets to reach the zone was the time taken to pass through the green zone, namely 1.05-1.65 s; 4) Similarly, when the range was $14 \mathrm{~m}<x \leq$ $17 \mathrm{~m}$, the time taken by droplets to reach the zone was the time taken to pass through the yellow zone, namely $1.8-2.25 \mathrm{~s} ; 5$ ) When the range was $17 \mathrm{~m}<x \leq 20 \mathrm{~m}$, due to a low airflow velocity, droplet flow continued drifting and diffusing slowly along $x$-axis under the action of inertia force and the time taken by droplets to reach the zone was the time taken to pass through the red zone, namely 2.4-3.0 s. It took about $3 \mathrm{~s}$ for droplets to move from $x=$ $0 \mathrm{~m}$ at the sprayer-duct outlet to $x=20 \mathrm{~m}$. As shown in the motion time diagram of droplet flow, the time taken by droplets to reach different targets can be predicted and based on this the running speed of sprayer can be calculated to realize excellent droplet deposition on the target.

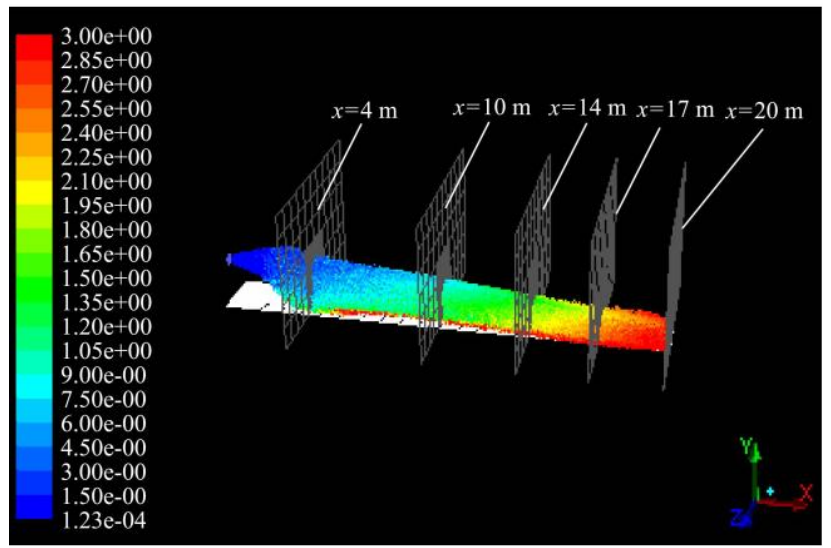

Figure 4 Motion time of droplet flow

4.2 Calculation Result and Analysis of Droplet Flow Parameters

To study the parameters of droplet flow in the spraying range of long-range air-blast sprayer, monitoring sections were set horizontally start at $x=1 \mathrm{~m}$ from the sprayer-duct outlet and every $0.5 \mathrm{~m}$ along the sprayer-duct axis. Parameters of droplet flow pas sing the sections were monitored and counted using Fluent simulating calculation. The distribution of monitoring sections is shown in Figure 5. Total number of droplets $n_{x}$, number of aerosols $n_{a x}$, number of mist $n_{b x}$, number of fine mist $n_{c x}$ and number of coarse mist $n_{d x}$ as well as maximum, minimum and average of droplet size $d_{x \max }, d_{x \min }$ and $d_{x a v r}$ at $x$ can be obtained from the monitoring section of Figure 5.

In order to study the motion distance of droplets of different sizes in the airflow field, airflow velocity at the sprayer-duct outlet was set as $25.01 \mathrm{~m} / \mathrm{s}$ and spray pressure was set as $1.8 \mathrm{MPa}$, quantitative distribution of aerosol, mist, fine mist and coarse mist on different monitoring sections were shown in Table 1 (The quantity of aerosols, mist, fine mist and coarse mist is, $n_{a x}, n_{b x}, n_{c x}$ and $n_{d x}$ respectively). It can be seen that the number of droplets decreased as droplets moved in the airflow field. The distance when the remaining number of droplets decreased to $10 \%$ of the initial number was the motion distance of droplets.

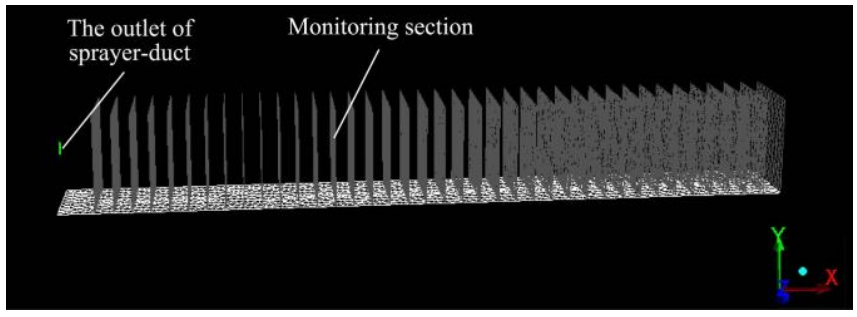

Figure 5 Distribution of monitoring sections

1) There were 20 aerosols (droplet size was less than $50 \mu \mathrm{m}$ ) on the initial monitoring section $x=1 \mathrm{~m}$. When $x \geq 18.5 \mathrm{~m}$, the remaining number of aerosols was less than $10 \%$ of the initial number, namely the maximum motion distance of aerosol droplets was $18.5 \mathrm{~m}$;

2) There were 11714 mists (droplet size was $50-100 \mu \mathrm{m}$ ) on $x=1 \mathrm{~m}$. When $x \geq 19.5 \mathrm{~m}$, the remaining number of mists was less than $10 \%$ of the initial number, namely the maximum motion distance of mists was $19.5 \mathrm{~m}$;

3) There were 234168 fine mists (droplet size was $100-400 \mu \mathrm{m}$ ) on $x=1 \mathrm{~m}$. When $x \geq 17.5 \mathrm{~m}$, the remaining number of fine mists was less than $10 \%$ of the initial number, namely the maximum motion distance of fine mists was $17.5 \mathrm{~m}$;

4) There were 18241 coarse mists (droplet size was greater than $400 \mu \mathrm{m}$ ) on $x=1 \mathrm{~m}$. When $x \geq 10.5 \mathrm{~m}$, the remaining number of coarse mists was less than $10 \%$ of the initial number, namely the maximum motion distance of coarse mists was $10.5 \mathrm{~m}$.

In order to study the density of droplet flow in airflow field along $x$-axis, two densities were defined, namely number density $\rho_{x n}$ and volume density $\rho_{x v}$ of droplet flow. The former represented the number of droplets per volume expressed using Equation (9) and the latter represented the volume occupied by droplets per volume expressed using Equation (10).

$$
\begin{gathered}
\rho_{x n}=\frac{n_{x}}{S d_{x a v r}} \\
\rho_{x v}=\frac{\rho_{x n} \frac{4}{3} \pi\left(\frac{d_{x a v r}}{2}\right)^{3}}{S d_{x a v r}}
\end{gathered}
$$

where, $\rho_{x n}$ is the number density of droplet, particle $/ \mathrm{m}^{3} ; n_{x}$ is the number of droplet on the monitoring section, particle; $S$ is the area of monitoring section, $\mathrm{m}^{2} ; d_{\text {xavr }}$ is the mean droplet size, $\mathrm{m} ; S d_{\text {xavr }}$ is the equivalent average volume of sample space, $\mathrm{m}^{3} ; \rho_{x v}$ is the dimensionless volume density of droplet.

Droplet flow parameters of different monitoring sections can be obtained from Equations (9) and (10), as shown in Table 1.

In order to understand parameter variation of droplets moving in the airflow field, the droplet flow parameter variation curve with the motion distance was drawn as shown in Figure 6 . Confined to the length of the paper, the authors focused on the mean droplet size (collectively referred to as droplet size) and corresponding number density and volume density of droplet flow (collectively referred to as number density and volume density of droplet flow) in this paper. Figure 6 showed that parameters of droplet flow from long-range air-blast sprayer changed with different distances along $x$-axis.

As shown in Table 1, droplet size gradually decreased with change in sampling position and change law of droplet size with different sampling positions was obtained with curve fitting and 
data regression analysis method. As shown in Figure 6a, droplet size and distance along $x$-axis were subject to the law of cubic polynomial function. Regression analysis was carried out with linear function, polynomial function, power function, logarithmic function and exponential function respectively during data analysis and the function equation with larger correlation coefficient $R^{2}$ and
$P$ value less than 0.001 in ANOVA was used as the regression function equation of droplet size varying with the $x$-axis distance. Similarly, the authors carried out a regression analysis of number, number density and volume density of droplet flow on different monitoring sections changing with the distance along $x$-axis and fitted corresponding regression function equation.

Table 1 Parameters of droplet flow on monitoring sections

\begin{tabular}{|c|c|c|c|c|c|c|c|c|}
\hline$x / \mathrm{m}$ & $d_{\text {xavr }} / \mu \mathrm{m}$ & $n_{a x} /$ particle & $n_{b x} /$ particle & $n_{c x} /$ particle & $n_{d x} /$ particle & $n_{x} /$ particle & $\rho_{\text {xnavr }} /$ particle $\cdot \mathrm{m}^{-3}$ & $\rho_{\text {xvavr }}$ \\
\hline 1.0 & 226.72 & 20 & 11714 & 234168 & 18241 & 264143 & $5.24 \mathrm{E}+07$ & 0.51 \\
\hline 1.5 & 226.85 & 20 & 11624 & 231203 & 18098 & 260945 & $5.17 \mathrm{E}+07$ & 0.50 \\
\hline 2.0 & 226.71 & 20 & 11496 & 226966 & 17870 & 256352 & $5.08 \mathrm{E}+07$ & 0.49 \\
\hline 2.5 & 225.90 & 20 & 11398 & 220876 & 17388 & 249682 & $4.97 \mathrm{E}+07$ & 0.48 \\
\hline 3.0 & 224.09 & 20 & 11268 & 212561 & 16504 & 240353 & $4.82 \mathrm{E}+07$ & 0.46 \\
\hline 3.5 & 220.93 & 20 & 11129 & 202393 & 15072 & 228614 & $4.65 \mathrm{E}+07$ & 0.43 \\
\hline 4.0 & 216.28 & 20 & 10996 & 190974 & 13030 & 215020 & $4.47 \mathrm{E}+07$ & 0.39 \\
\hline 4.5 & 210.47 & 20 & 10857 & 179567 & 10717 & 201161 & $4.30 \mathrm{E}+07$ & 0.36 \\
\hline 5.0 & 204.49 & 20 & 10727 & 169896 & 8310 & 188953 & $4.15 \mathrm{E}+07$ & 0.33 \\
\hline 5.5 & 199.43 & 19 & 10580 & 162020 & 6435 & 179054 & $4.04 \mathrm{E}+07$ & 0.30 \\
\hline 6.0 & 195.52 & 12 & 10441 & 155321 & 5139 & 170913 & $3.93 \mathrm{E}+07$ & 0.28 \\
\hline 6.5 & 192.58 & 12 & 10257 & 149081 & 4327 & 163677 & $3.82 \mathrm{E}+07$ & 0.27 \\
\hline 7.0 & 190.25 & 12 & 10057 & 143191 & 3796 & 157056 & $3.71 \mathrm{E}+07$ & 0.25 \\
\hline 7.5 & 188.34 & 12 & 9850 & 137441 & 3392 & 150695 & $3.60 \mathrm{E}+07$ & 0.24 \\
\hline 8.0 & 186.68 & 9 & 9609 & 131678 & 3055 & 144351 & $3.48 \mathrm{E}+07$ & 0.23 \\
\hline 8.5 & 185.07 & 8 & 9374 & 125907 & 2769 & 138058 & $3.35 \mathrm{E}+07$ & 0.22 \\
\hline 9.0 & 183.72 & 8 & 9076 & 120303 & 2526 & 131913 & $3.23 \mathrm{E}+07$ & 0.21 \\
\hline 9.5 & 182.33 & 8 & 8765 & 114429 & 2306 & 125508 & $3.09 \mathrm{E}+07$ & 0.19 \\
\hline 10.0 & 180.89 & 8 & 8481 & 108671 & 2095 & 119255 & $2.96 \mathrm{E}+07$ & 0.18 \\
\hline 10.5 & 179.65 & 8 & 8149 & 102886 & 1916 & 112959 & $2.83 \mathrm{E}+07$ & 0.17 \\
\hline 11 & 178.40 & 8 & 7824 & 97090 & 1739 & 106661 & $2.69 \mathrm{E}+07$ & 0.16 \\
\hline 11.5 & 177.26 & 8 & 7452 & 91113 & 1579 & 100152 & $2.54 \mathrm{E}+07$ & 0.15 \\
\hline 12 & 175.81 & 8 & 7130 & 84981 & 1420 & 93539 & $2.39 \mathrm{E}+07$ & 0.14 \\
\hline 12.5 & 174.58 & 8 & 6809 & 78957 & 1291 & 87065 & $2.24 \mathrm{E}+07$ & 0.13 \\
\hline 13 & 173.36 & 4 & 6415 & 73071 & 1141 & 80631 & $2.09 \mathrm{E}+07$ & 0.12 \\
\hline 13.5 & 172.02 & 4 & 6019 & 67249 & 1006 & 74278 & $1.94 \mathrm{E}+07$ & 0.11 \\
\hline 14 & 170.72 & 4 & 5636 & 61237 & 886 & 67763 & $1.78 \mathrm{E}+07$ & 0.10 \\
\hline 14.5 & 169.07 & 4 & 5259 & 55526 & 748 & 61537 & $1.64 \mathrm{E}+07$ & 0.09 \\
\hline 15 & 167.55 & 4 & 4893 & 49946 & 654 & 55497 & $1.49 \mathrm{E}+07$ & 0.08 \\
\hline 15.5 & 165.92 & 4 & 4531 & 44186 & 567 & 49288 & $1.34 \mathrm{E}+07$ & 0.07 \\
\hline 16 & 164.40 & 4 & 4104 & 38808 & 479 & 43395 & $1.19 \mathrm{E}+07$ & 0.06 \\
\hline 16.5 & 162.52 & 4 & 3713 & 33561 & 391 & 37669 & $1.04 \mathrm{E}+07$ & 0.05 \\
\hline 17 & 160.68 & 4 & 3296 & 28541 & 311 & 32152 & $9.00 \mathrm{E}+06$ & 0.04 \\
\hline 17.5 & 158.88 & 4 & 2861 & 23627 & 253 & 26745 & $7.57 \mathrm{E}+06$ & 0.04 \\
\hline 18 & 157.21 & 4 & 2420 & 18998 & 194 & 21616 & $6.18 \mathrm{E}+06$ & 0.03 \\
\hline 18.5 & 155.37 & 3 & 1958 & 14865 & 138 & 16964 & $4.91 \mathrm{E}+06$ & 0.02 \\
\hline 19 & 152.97 & 0 & 1452 & 11013 & 92 & 12557 & $3.69 \mathrm{E}+06$ & 0.02 \\
\hline 19.5 & 150.28 & 0 & 1027 & 7495 & 57 & 8579 & $2.57 \mathrm{E}+06$ & 0.01 \\
\hline 20 & 146.56 & 0 & 635 & 4607 & 22 & 5264 & $1.61 \mathrm{E}+06$ & 0.01 \\
\hline
\end{tabular}

As shown in Figure 6a, droplet size decreased at varying rates in different zones from the sprayer-duct outlet. 1) When the range was $1 \mathrm{~m} \leq x<3 \mathrm{~m}$, droplet size decreased slowly. It's mainly because the droplets from the nozzle had a larger initial velocity under spray pressure, at the same time, there is a high speed of airflow along the positive direction of $x$-axis, as droplets collided with relatively static airflow when moving in the positive direction of $x$-axis. However, droplet size decreased slowly due to a small airflow resistance in the positive direction of $x$-axis and little collision between droplet and relatively static air; 2) When the range was $3 \mathrm{~m} \leq x<8 \mathrm{~m}$, droplet size decreased more rapidly. It's mainly because the droplets obtained kinetic energy under spray pressure and airflow, as the distance from the sprayer-duct outlet increased, the speed of both droplet and airflow along the positive direction of $x$ decreased, but the speed of droplet decreased more slowly than that of airflow due to inertia. When droplet moved faster than airflow, it is easier for droplets to collide with relatively static airflow and droplet size decreased more rapidly under shear action and perturbation action of airflow; 3) When the range was $8 \mathrm{~m} \leq x \leq 20 \mathrm{~m}$, droplet size decreased more slowly. As stated 
above, although droplets moved faster than airflow in this zone, the speed of droplets and airflow decelerated along the positive direction of $x$-axis as the distance from the sprayer-duct outlet further increased and the collision force between droplet and relatively static airflow weakened, so the droplet size decreased more slowly.

As shown in Figure 6b, the number of droplets on different monitoring sections gradually decreased with increase in the motion distance of droplets along $x$-axis. It's mainly because: 1 ) Some droplets with a larger size settled to the ground under gravity when moving along $x$-axis; 2) As the distance from the sprayer-duct outlet increased, airflow velocity and kinetic energy obtained by droplets under airflow action gradually decreased, strength against airflow resistance gradually weakened and the number of droplets moving farther decreased. Similarly, number density of droplet flow also decreased relatively evenly with increase in the motion distance along $x$-axis. The variation curve is shown in Figure 6c.

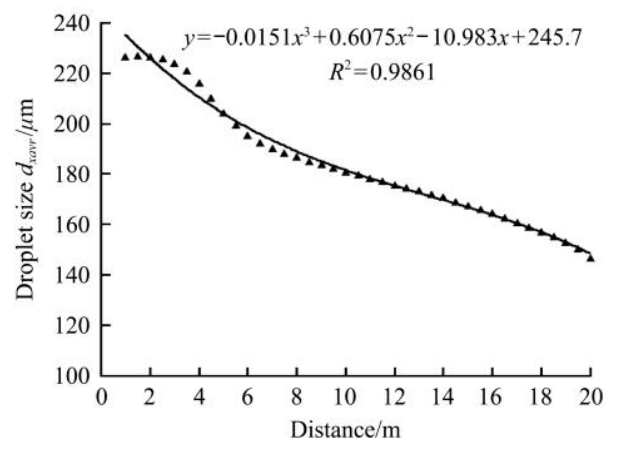

a. Relation between droplet size and motion distance

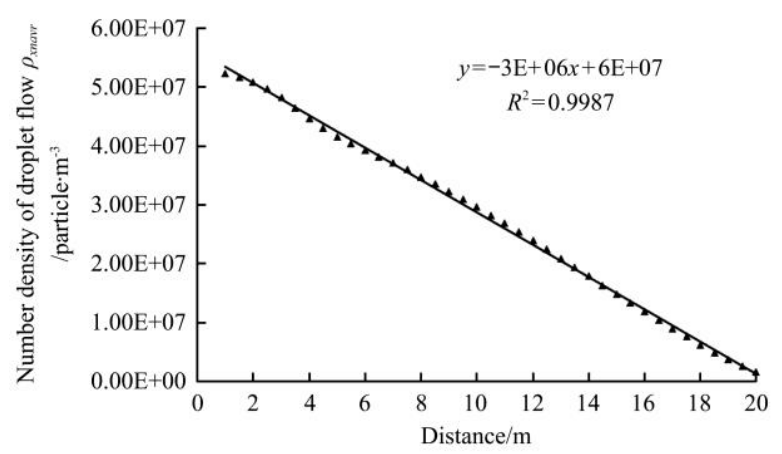

c. Relation between number density of droplet flow and motion distance
As shown in Figure 6d, the volume density of droplet flow gradually decreased at varying rates with increase in the motion distance along $x$-axis. 1) When the range was $1 \mathrm{~m} \leq x<3 \mathrm{~m}$, the volume density of droplet flow decreased relatively slowly. It's probably because droplets from the nozzle had a larger initial velocity under spray pressure and airflow produced by the sprayer-duct also had a larger speed, most droplets moved along $x$-axis and less droplets settled to the ground under gravity; 2) When the range was $3 \mathrm{~m} \leq x<8 \mathrm{~m}$, more large droplets settled to the ground under gravity when droplet velocity decelerating along $x$-axis. Therefore, the volume density of droplet flow decreased more rapidly, even though its number density decreased evenly; 3 ) When the range was $8 \mathrm{~m} \leq x \leq 20 \mathrm{~m}$, the volume density of droplet flow decreased relatively steadily. The droplets size and number density of droplet flow in this zone decreased relatively steadily, so the number of droplets with a larger size settling to the ground remained relatively stable. Volume density of droplet flow with change in the distance along $x$-axis is shown in Figure 6d.

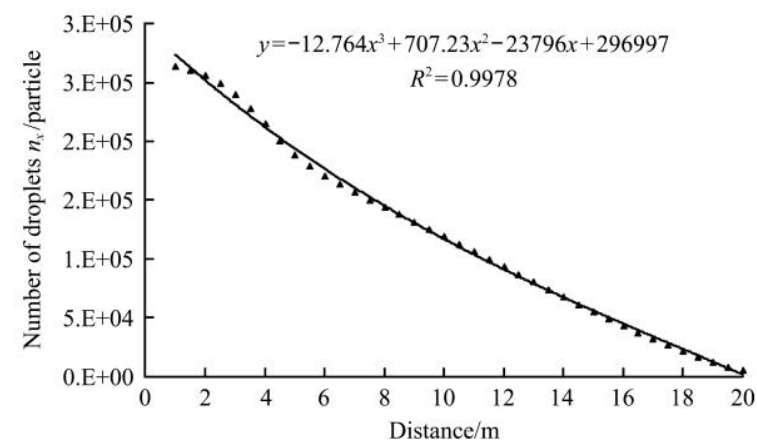

b. Relation between number of droplets and motion distance

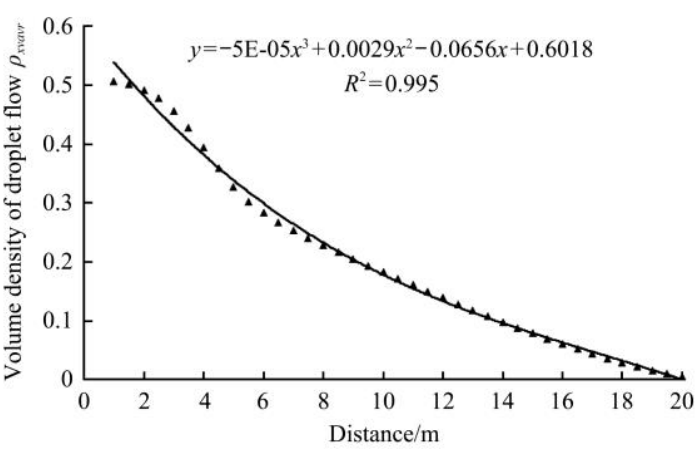

d. Relation between volume density of droplet flow and motion distance

Figure 6 Variation curve of droplet flow parameters with motion distance

\section{Verification experiment of simulation model}

In order to verify the correctness of the simulation model and simulation results in this paper, the verification droplet deposition experiment was carried out, and the droplet deposition experiment scene of air-blast sprayer is shown in Figure 7. When there was no sustained natural wind in the outdoors, the stainless steel sampling dishes were placed on the ground at intervals of $0.5 \mathrm{~m}$ starting from the vertical bottom of the nozzles on the axial direction of the sprayer duct, and continue to spray for two minutes. After spraying, the mass of the sampling dishes before and after the experiment were measured, and the droplet deposition values at the sampling dishes were obtained. The measured values of droplet deposition are shown in the fourth line of Table 2.

According to droplet sampling method used in the actual droplet deposition experiment, circular sections were built as the droplet deposition sections in the simulating model according to the position and size of sampling dishes in the actual droplet deposition experiment to calculate the diameter and number of droplets. As a result, the mass sum of droplets on each section can be calculated as the simulation value of droplet deposition at each sampling point, as shown in the second line of Table 2. Due to the limited computing resources, in the simulation experiment of droplet deposition, the program converges steadily over 20000 iterations, and then the simulation values of droplet deposition were obtained from the following 10000 iterations.

In order to ensure the comparability between the simulated and measured values of droplet deposition, the droplet deposition values in the above two cases were normalized. The normalized equations are shown in Equation (11):

$$
\begin{aligned}
W^{*}{ }_{i} & =\frac{W_{i}}{\max \left\{W_{i}\right\}} \\
W^{*}{ }_{o i} & =\frac{W_{o i}}{\max \left\{W_{o i}\right\}}
\end{aligned}
$$


where, $W_{i}$ is the simulation value of droplet deposition, $\mathrm{g} ; W^{*}{ }_{i}$ is the normalized simulation value of droplet deposition, dimensionless parameter; $W_{o i}$ is the measured value of droplet deposition, $\mathrm{g} ; W^{*}{ }_{o i}$ is the normalized measured value of droplet deposition, dimensionless parameter.

After normalization, the normalized simulation values of droplet deposition were obtained as shown in the third line of Table 2 , the normalized measured values of droplet deposition were obtained as shown in the fifth line of Table 2.

In order to verify correctness of the simulation results in this paper, the authors carried out chi-square analysis of the normalized simulation values and the normalized measured values of droplet deposition in Table 2, so as to verify whether both had statistical significant differences. The calculation equation is shown in Equation (12):

$$
\chi^{2}=\sum_{i=1}^{m} \frac{\left(W_{i}^{*}-W_{o i}^{*}\right)^{2}}{W_{o i}^{*}}
$$

where, $m$ is the number of observe values and it is $m=21$. The critical value is $\chi_{0.05}^{2}(m-1)$ by looking up $\chi^{2}$ checklist. Suppose $\chi^{2}$ calculated by Equation (12) is less than $\chi_{0.05}^{2}(m-1)$, it means that the distribution of the normalized simulation values of droplet deposition is subject to the distribution of the normalized measured values at the significant level of 0.05 , and vice versa.

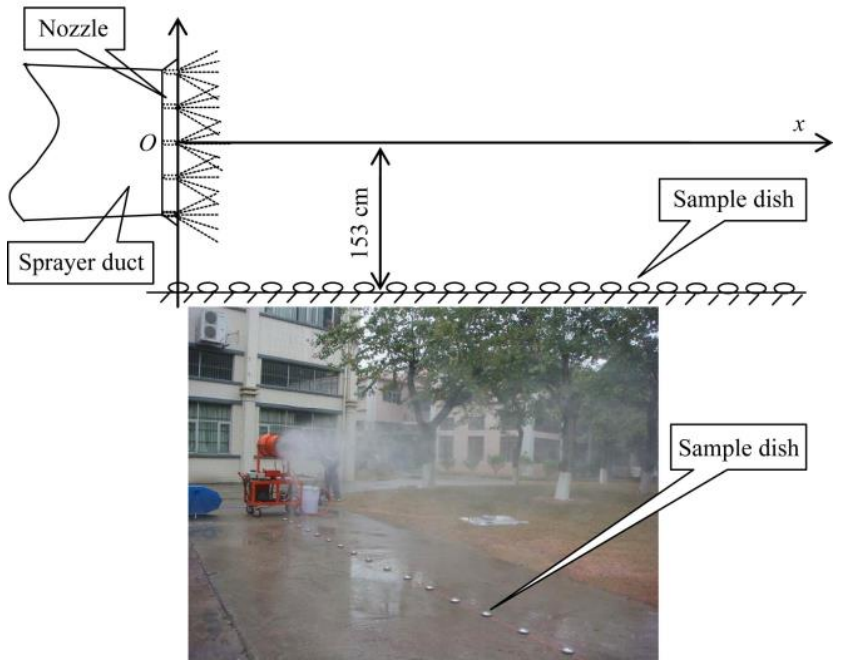

Figure 7 Droplet deposition experiment scene of air-blast sprayer

Table 2 Simulated and measured value of droplet deposition in different sampling points and their normalized results

\begin{tabular}{|c|c|c|c|c|c|c|c|c|c|c|c|c|c|c|c|c|c|c|c|c|c|}
\hline$x / \mathrm{m}$ & 0 & 0.5 & 1 & 1.5 & 2 & 2.5 & 3 & 3.5 & 4 & 4.5 & 5 & 5.5 & 6 & 6.5 & 7 & 7.5 & 8 & 8.5 & 9 & 9.5 & 10 \\
\hline $\begin{array}{l}\text { Simulation value of } \\
\text { droplet deposition/g }\end{array}$ & 0.00 & 0.00 & $\begin{array}{l}2.02 \\
\text { E-04 }\end{array}$ & $\begin{array}{l}2.50 \\
\text { E- } 03\end{array}$ & $\begin{array}{l}3.39 \\
\text { E- } 03\end{array}$ & $\begin{array}{l}4.06 \\
\text { E-03 }\end{array}$ & $\begin{array}{l}4.03 \\
\mathrm{E}-03\end{array}$ & $\begin{array}{l}2.19 \\
\text { E-03 }\end{array}$ & $\begin{array}{c}1.62 \\
\mathrm{E}-03\end{array}$ & $\begin{array}{l}1.09 \\
\mathrm{E}-03\end{array}$ & $\begin{array}{l}8.05 \\
\text { E-04 }\end{array}$ & $\begin{array}{l}9.36 \\
\text { E- } 04\end{array}$ & $\begin{array}{l}8.23 \\
\text { E-04 }\end{array}$ & $\begin{array}{l}9.20 \\
\mathrm{E}-04\end{array}$ & $\begin{array}{l}4.80 \\
\mathrm{E}-04\end{array}$ & $\begin{array}{l}7.71 \\
\text { E-04 }\end{array}$ & $\begin{array}{l}9.58 \\
\mathrm{E}-04\end{array}$ & $\begin{array}{l}6.68 \\
\text { E-04 }\end{array}$ & $\begin{array}{l}1.13 \\
\mathrm{E}-03\end{array}$ & $\begin{array}{l}8.73 \\
\text { E-04 }\end{array}$ & $\begin{array}{r}1.06 \\
\text { E-03 }\end{array}$ \\
\hline $\begin{array}{l}\text { Normalized simulation } \\
\text { values of droplet deposition }\end{array}$ & 0.00 & 0.00 & 0.05 & 0.62 & 0.84 & 1.00 & 0.99 & 0.54 & 0.40 & 0.27 & 0.20 & 0.23 & 0.20 & 0.23 & 0.12 & 0.19 & 0.24 & 0.17 & 0.29 & 0.22 & 0.26 \\
\hline $\begin{array}{l}\text { Measured value of } \\
\text { droplet deposition/g }\end{array}$ & 1 & 1 & 2 & 14 & 22.5 & 20 & 12.5 & 8.5 & 7.5 & 7 & 5.5 & 6.5 & 6.5 & 7 & 7.5 & 6.5 & 6.5 & 6.5 & 5.5 & 6.5 & 5.5 \\
\hline
\end{tabular}

Based on two groups of values in the third and fifth lines of Table $2, \chi^{2}=0.91$ by calculation and $\chi_{0.05}^{2}(m-1)=31.41$ by looking up $\chi^{2}$ checklist. It indicated that the distribution of the normalized simulation values of droplet deposition are subject to distribution of the normalized measured values and the simulation model adopted in this paper is credible for analysis of droplet flow data and droplet deposition result in the airflow field.

\section{Conclusions}

The change law of droplet size, number of droplets, number density and volume density of droplet flow and droplet deposition in different distance of spraying range under the airflow action of long-range air-blast sprayer were studied through CFD simulation, and parameter variation of droplet flow in the airflow field were analyzed. Conclusions are drawn as below:

(1) Droplets under the airflow action are distributed hierarchically with increase in the distance of spraying range. Droplets with a larger size settle at the bottom and those with smaller size are transported by airflow farther. Long-range air-blast sprayer has a significant effect on directional transport of small droplets;

(2) The spraying swath of droplet flow vertical to the spraying range direction gradually enlarged with the increase in the distance of spraying range and droplets mainly pervade and drift at the end of the range;

(3) Gravity has an obvious effect on droplet and droplets with a larger size settle faster;

(4) Given that outlet airflow velocity was $25.01 \mathrm{~m} / \mathrm{s}$ and the spray pressure was $1.8 \mathrm{MPa}$, the maximum motion distance of aerosol, mist, fine mist and coarse mist in the airflow field was $18.5 \mathrm{~m}, 19.5 \mathrm{~m}, 17.5 \mathrm{~m}$ and $10.5 \mathrm{~m}$ respectively;
(5) Under the airflow action, change in droplet size, number of droplets, number density and volume density of droplet flow with spraying range distance of the sprayer shows a regression function relationship;

(6) Chi-square test on the simulation result and the measured result of droplet deposition indicated that the simulation result of the model adopted in this paper was reliable.

(7) Because of the airflow action of long-range air-blast sprayer, the droplet flow undergoes a directional motion. In this paper, change law of droplet size, number of droplets, number density and volume density of droplet flow and droplet deposition with different spraying range distance of the sprayer were obtained by simulation, which could provide important guidance for reducing the drift of droplets in air-blast spraying technology and reducing environmental pollution from pesticides and optimizing spray effects. Besides, the reliability of the CFD simulation model has been verified in this paper. Using this model to simulate, which could replace the actual field experiment, reduce the cost of spraying experiment materials for long-range air-blast sprayer and shorten the experiment cycle.

\section{Acknowledgements}

The authors gratefully acknowledge the financial support provided by the National Natural Science Foundation of China (Grant No. 31671591), Guangdong Provincial Special Fund for Modern Agriculture Industry Technology Innovation Teams (2020KJ108), Guangdong Provincial Department of Agriculture 2018 Provincial Rural Revitalization Strategy Special Fund (YUE CAI NONG [2018] No.125) and Special Fund for the Construction of Modern Agricultural Technology System (CARS-27). 


\section{[References]}

[1] Farooq M, Salyani M. Spray penetration into the citrus tree canopy from two air-carrier sprayers. Trans. ASABE, 2002; 45(5): 1287-1293.

[2] Dai F F. Brief introduction to development trend of pesticide application technology in China. Plant Protection, 2004; 30(4): 5-8. (in Chinese)

[3] He X K. Improving severe draggling actuality of plant protection machinery and its application techniques. Transactions of the CSAE, 2004; 20(1): 13-15. (in Chinese)

[4] Liu J. The study about appliance and technology of cannon rotary-atomizing long-shot air-assisted spraying. Master dissertation. Yangling: Northwest A\&F University, 2004; 65p. (in Chinese)

[5] Guo F, Chen J D, Guo H, Han C J, Cheng J C, Yang W Z. Performance optimization and advance of $3 \mathrm{WF}-8$ air-assisted orchard sprayer. Journal of Agricultural Mechanization Research, 2010; 32(11): 48-56. (in Chinese)

[6] Liu Q, Fu Z T, Qi L J, Shi J X, Chen F. Characteristics optimization experiments of 9WZCD-25 air-blast and ultra low volume sprayer. Transactions of the CSAM, 2005; 36(9): 44-47. (in Chinese)

[7] Ding T H, Cao S M, Xue X Y, Ding S M, Zhou L F, Qiao B Y. Simulation and experiment on single-channel and double-channel airflow field of orchard sprayer. Transactions of the CSAE, 2016; 32(14): 62-68. (in Chinese)

[8] Fu Z T, Wang J, Qi L J, Wang H T. CFD simulation and experimental verification of air-velocity distribution of air assisted orchard sprayer. Transactions of the CSAE, 2009; 25(1): 69-74. (in Chinese)

[9] Song S R, Xia H B, Lu Y H, Hong T S, Ruan Y C. Structural optimization and experiment on fluid director of air-assisted sprayer. Transactions of the CSAE, 2012; 28(6): 7-12. (in Chinese)

[10] Song S R, Xia H B, Liu H S, Hong T S, Sun D Z, Lu Y H. Numerical simulation and experiment of structural optimization for air blast sprayer. Transactions of the CSAM, 2013; 44(6): 73-78, 55. (in Chinese)

[11] Song S R, Ruan Y C, Hong T S, Dai Q F, Xiahou B. Optimal design and test on expanding duct of wide-swath air-blast sprayer. Transactions of the CSAE, 2013; 29(18): 34-42. (in Chinese)

[12] Song S R, Hong T S, Liu H S, Ruan Y C, Chen J Z. Law of spatial airflow velocity distribution for wide-swath air-blast sprayer. Transactions of the CSAE, 2013; 29(24): 17-24. (in Chinese)

[13] Chen F Y, Wang X C, Ding W M, Fu X M, Lv X L, He G M. Numerical simulation and experimental verification of 3D air-velocity field of disk fan used in orchard sprayer. Transactions of the CSAM, 2010; 41(8): 51-54. (in Chinese)

[14] Endalew M A, Debaer C, Rutten N, Vercammen J, Delele M A, Ramon H, et al. A new integrated CFD modeling approach towards air-assisted orchard spraying. Part I: Model development and effect of wind speed and direction on sprayer airflow. Comput. Electron. Agric., 2010; 71(2): 128-136.

[15] Delele M A, De Moor A, Sonck B, Ramon H, Nicolai B M, Verboven P. Modelling and validation of the air flow generated by a cross flow air sprayer as affected by travel speed and fan speed. Biosystems Engineering, 2005; 92(2): 165-174.
[16] Dekeyser D, Foque D, Duga A T, Verboven P, Hendrickx N, Nuyttens D Spray deposition assessment using different application techniques in artificial orchard trees. Crop Protection, 2014; 64: 187-197.

[17] Qi L J, Zhao Y Q, Wang J, Ji R H, Mang L. CFD simulation and experimental verification of droplet dispersion of air-assisted orchard prayer. Transactions of the CSAM, 2010; 41(2): 62-67. (in Chinese)

[18] Cui Z H, Fu Z T, Qi L J, Wang J. Effect of the air duct medication on the spray drift emitted by an air-assisted sprayer. Transactions of the CSAE, 2008; 24(2): 111-115. (in Chinese)

[19] Wang J X, Qi L J, Xia Q J. CFD simulation and validation of trajectory and deposition behavior of droplets around target affected by air flow field in greenhouse. Transactions of the CSAE, 2015; 31(11): 46-53. (in Chinese)

[20] Lv X L, Fu X M, Song J L, He X K. Influence of spray operating parameters on spray drift. Transactions of the CSAM, 2011; 42(1): 59-63. (in Chinese)

[21] Lv X L, Fu X M, Wu P, Ding S M, Zhou L F, Yan H J. Influence of spray operating parameters on droplet deposition. Transactions of the CSAM, 2011; 42(6): 70-75. (in Chinese)

[22] He X K, Zeng A J, He J. Effect of wind velocity from orchard sprayer on droplet deposit and distribution. Transactions of the CSAE, 2002; 18(4): 75-77. (in Chinese)

[23] Delele M A, Jaeken P, Debaer C, Baetens K, Endalew M A, Ramon H, et al. CFD prototyping of an air-assisted orchard sprayer aimed at drift reduction. Comput. Electron. Agric., 2007; 55(1): 16-27.

[24] Salyani M. Optimization of deposition efficiency for air-blast sprayers. Transactions of the ASAE, 2000; 43(2): 247-253.

[25] Larbi P A, Salyani M. Model to predict spray deposition in citrus air-blast sprayer applications: part 1. Spray dispersion. Transactions of the ASABE, 2012; 55(1): 29-39.

[26] Ramon S, Ariane V, Rafael G, Cruz G, Enrique M, Patricia C. Eulerian-Lagrangian model of the behaviour of droplets produced by an air-assisted sprayer in a citrus orchard. Biosystems Engineering, 2017; 154: 76-91.

[27] Zhu H J. Fluent 15.0 practical guidelines for flow field analysis. Posts and Telecommunications Press, 2015; 503p. (in Chinese)

[28] Tang J P. Fluent 14.0 super study guide. Posts and Telecommunications Press, 2013; 460p. (in Chinese)

[29] Song S R. Optimization research on air-blast sprayer duct and spraying effect. Guangzhou: South China Agricultural University, 2012. (in Chinese)

[30] Liu H B. The car flow field CFD simulation and analysis of aerodynamic characteristics. Master dissertation. Lanzhou: Lanzhou University of Technology, 2013; 68p. (in Chinese)

[31] Duan Z Z. Flow field analysis and project examples of ANSYS Fluent. Beijing: Publishing House of Electronics Industry, 2015; 439p. (in Chinese)

[32] ANSYS Fluent. 14.5 user's guide. Canonsburg, PA: ANSYS, 2012.

[33] Zhang M Y, Jing S R, Li G J. Fluid dynamics of higher engineering. Higher Education Press, 2012; 532p. (in Chinese) 